\title{
HISTORIA DE LA CIRUGÍA
}

\section{Semblanza del Prof. Dr. Raúl Praderi \\ 18 de Setiembre de 1927 - $1^{\circ}$ de Agosto de 2014 \\ Maestro de cirujanos y conductor de hombres}

Semblance of Prof. Dr. Raúl Praderi

September 18, 1927 - August 1, 2014

Master of surgeons and men's leader

DOI: $10.31837 /$ cir.urug/3.1.6

Cincuenta meses ha, emprendía su vuelo definitivo quien rememorando a John B. Murphy, supo ser el petrel de la cirugía nacional. Hombre de características inusuales para este período histórico de nuestra profesión y nuestra cultura, había nacido en Montevideo, hijo de un distinguido pediatra y sindicalista, el Dr. José Alberto Praderi y de la Sra. Amalia González.

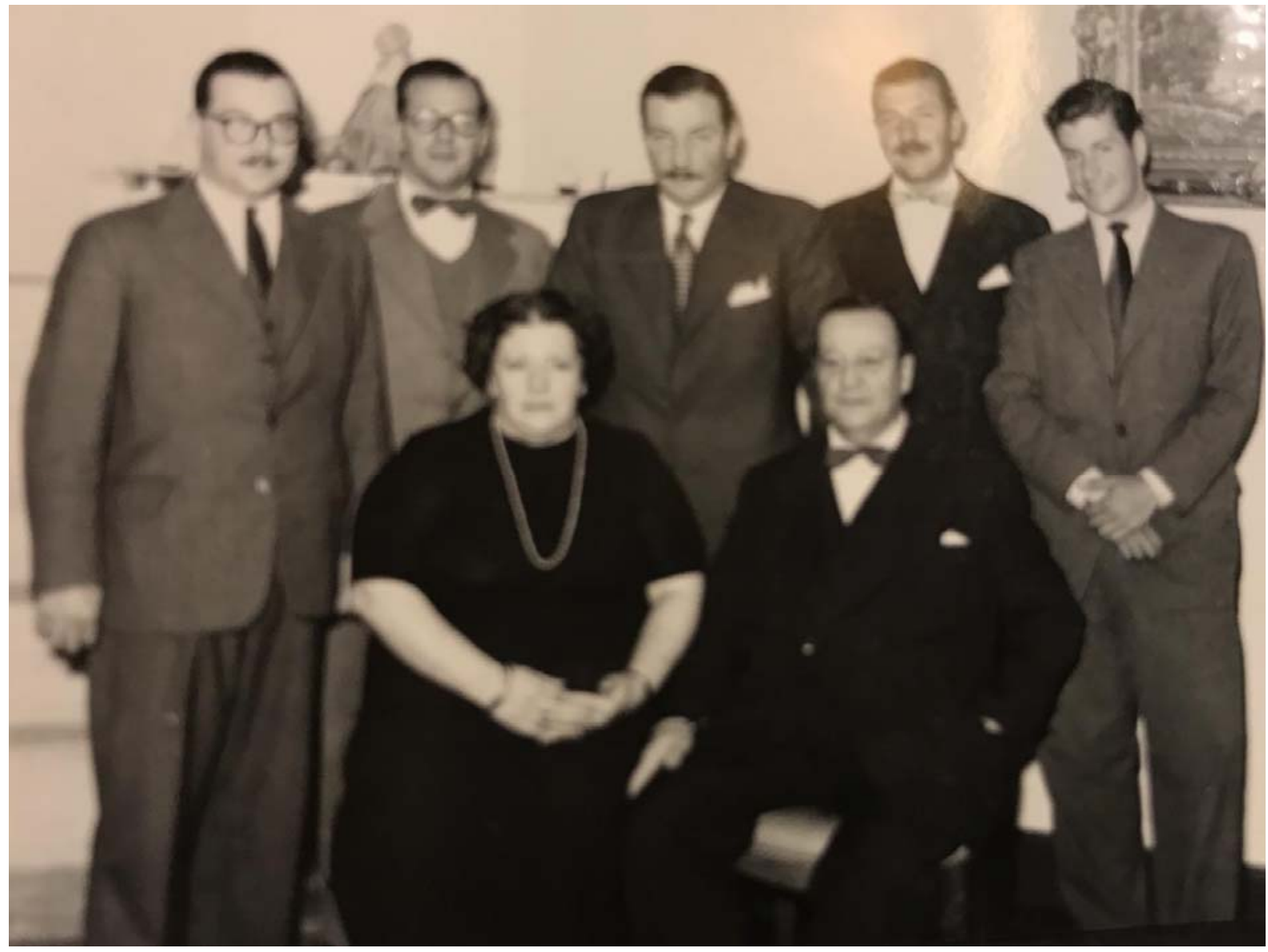

Foto 1 
Fue el tercero y más longevo de cinco hermanos, todos ellos universitarios, uno de ellos Luis, de distinguida carrera en la cirugía fue también Profesor de Clínica Quirúrgica.

El Profesor Praderi recibió su educación primaria en el Colegio Elbio Fernández y cursó secundaria en el Liceo Rodó en la época en que la educación pública no tenía parangón en nuestro país y allí comenzó a imbuir su espíritu en las ciencias naturales, la historia y la geografía, materias que amaba y continuó cultivando a lo largo de toda su existencia.

Ingresó a la Facultad de Medicina en 1945, obtuvo su título en 1956. Se dedicó a la docencia ocupando todos los cargos por concurso, haciendo honor a su condición de universitario y a la prédica gremial que distinguió a su padre.

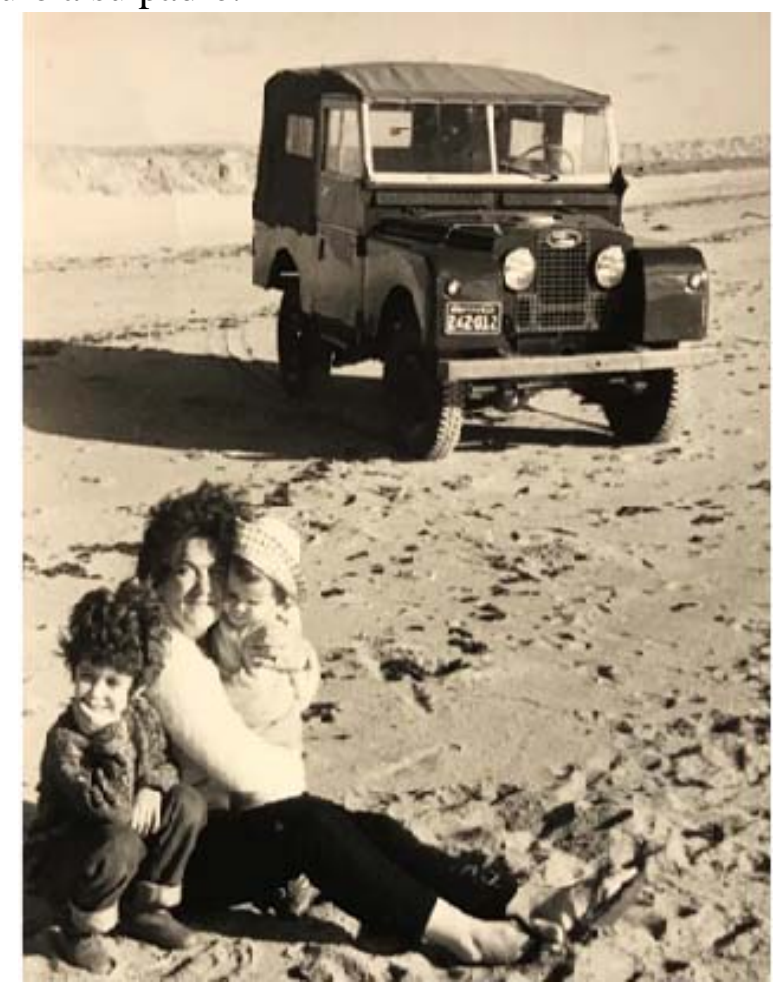

Foto 2

Una enumeración no exhaustiva de los más relevantes, comprende:

Disector y luego Prosector de Anatomía Normal.

Ayudante de Patología Quirúrgica, Asistente de Medicina Operatoria y luego Profesor Agregado del Departamento Básico de Cirugía y Laboratorio de Cirugía Experimental Asistente de la Clínica Quirúrgica “A” del Prof. Abel Chifflet y luegoProfesor Adjunto de la misma Clínica Quirúrgica.

Asistente Cirujano y luego Profesor Adjunto Cirujano del Departamento de Emergencia del Hospital de Clínicas. 
Profesor Agregado de Clínica Quirúrgica "B", culminando su carrera como Profesor Director de Clínica Quirúrgica “3”.

Concomitantemente concursó y desempeñó la carrera quirúrgica de Salud Pública.

Practicante Interno del Ministerio de Salud Pública. Cirujano de Sala en el Hospital Pasteur Servicio del Dr. Nin y Silva posteriormente Cirujano de Guardia del mismo hospital.

Si se me permite una anécdota personal, la vida me eligió a mis 14 o 15 años para hoy honrar la memoria de este Maestro de Hombres. Selman Waskman, descubridor de la estreptomicina y premio Nóbel; fue operado de apendicitis aguda en Uruguay.

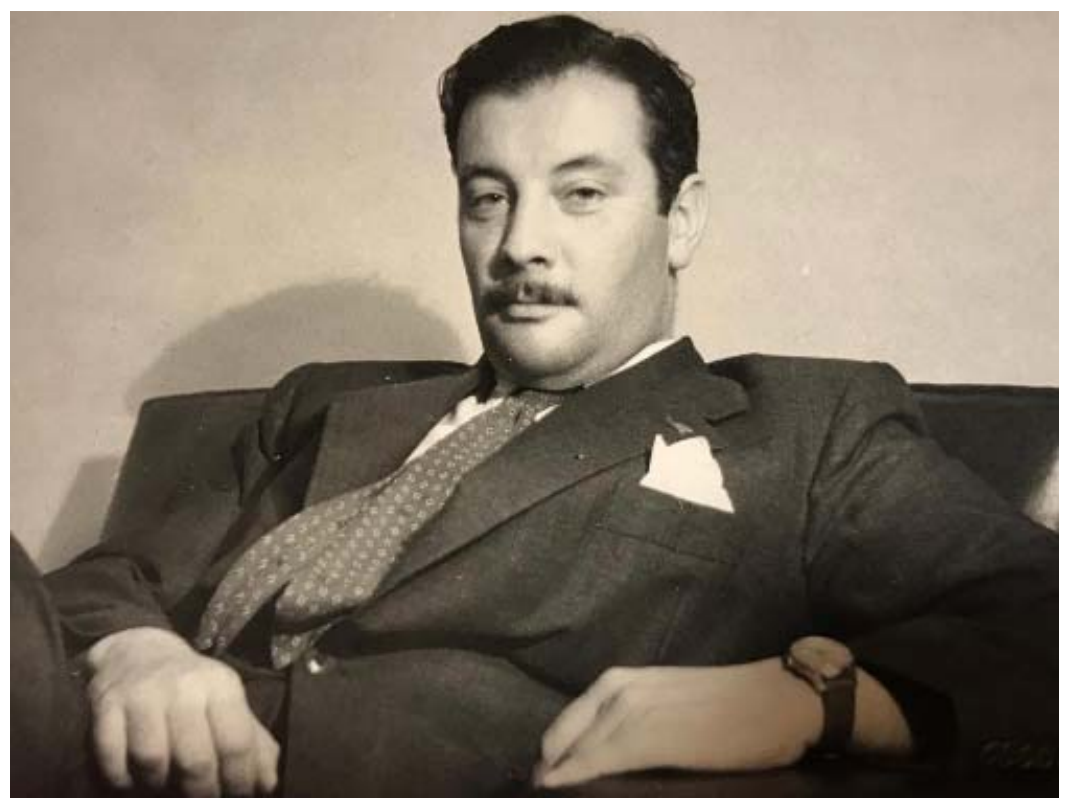

Foto 3

Invitado a tomar el té a la residencia de su cirujano el Prof. Abel Chifflet, este le pidió a su alumno Dr. Praderi que le diera una visión panorámica de nuestro país. Mi primo 4 años mayor a la sazón, estudiante de medicina y yo liceal que lo imitaba en la medida de mis posibilidades, fuimos a abrirle la puerta a un señor fornido, de imponente bigote que se bajó de un Land Rover acompañado de Marta,su señora, con varias cajas de diapositivas.

Después de un extenso recorrido fotográfico de nuestra tierra y cuando se retiraban, los acompañamos a la puerta y ahí le dije a mi primo y esto es textual: "Voy a ser cirujano, voy a usar bigote, voy a hacerme una canoa y voy a tener un Land Rover”. Todo ello lo cumplí y ese encuentro hasta hoy imborrable definió mi vida.

Como verán un conductor de hombres, que nunca pareció darse cuenta de ello. 
Con su designación como Profesor de Clínica, se suscitó un hecho singular. La Clínica Quirúrgica “3" no existía al momento de proveerse un cargo de profesor y tal fue la convicción de la injusticia que se cometía al no designarlo, que las autoridades universitarias, decidieron reactivar una segunda clínica quirúrgica en el primer hospital del país, el Maciel para que Praderi la ocupara.

En el momento que ingresamos a dicho hospital, el mismo carecía hasta de un laboratorio que pudiera realizar un estudio de crasis sanguínea, que nos permitiera anticoagular a los enfermos con riesgo de tromboembolismo postoperatorio. Aquellos con más de dos factores de riesgo de

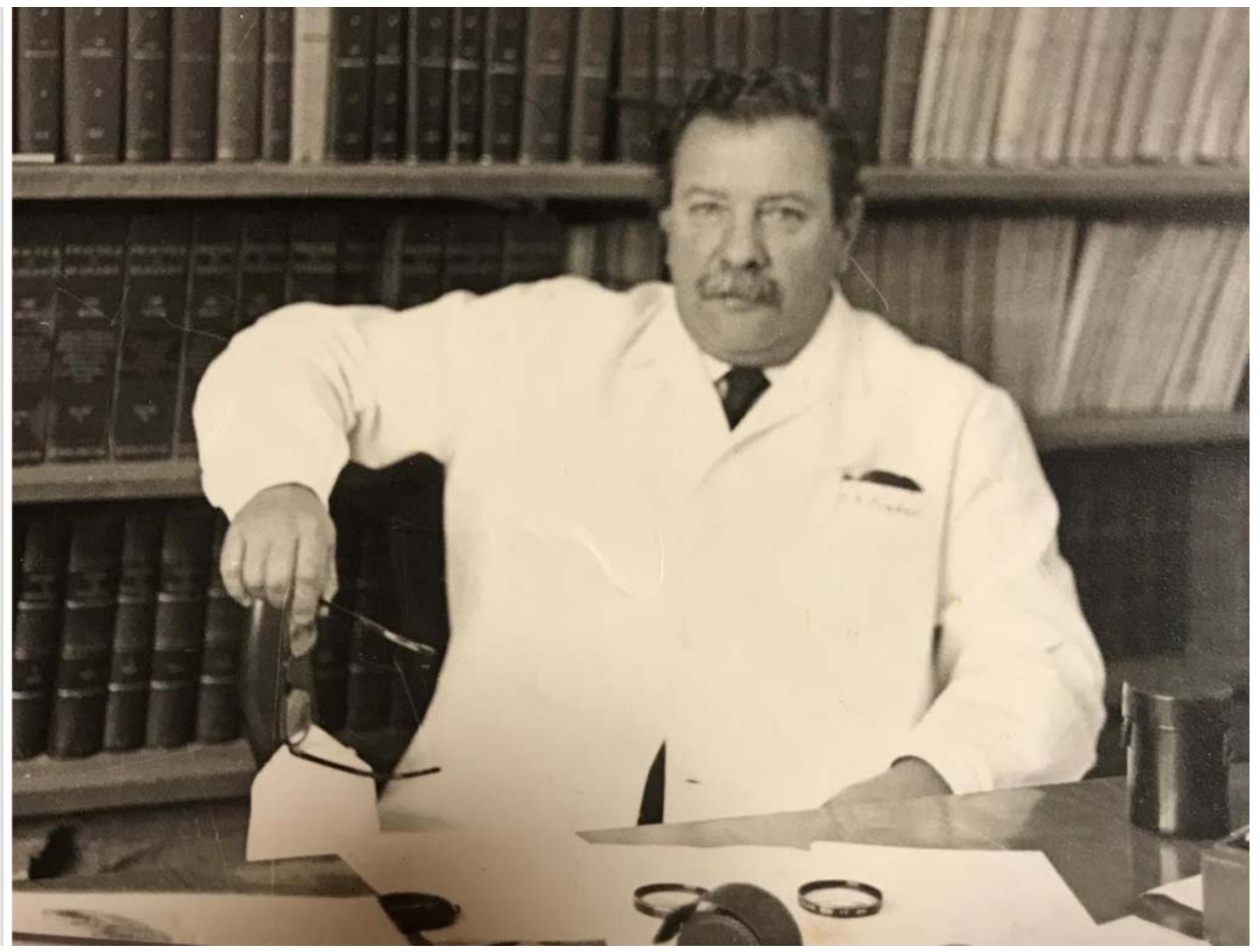

Foto 4

tromboembolismo pulmonar. les plicábamos la vena cava inferior como prevención, en la misma intervención. Cuando el Dr. Praderi se retiró, ya era el hospital público con mayor volumen quirúrgico del pais, con el laboratorio y el Servicio de Imagenología más moderno.

Supo ahí conformar un grupo humano unido, al que interesó en el estudio y en la investigación. Promovió el espíritu crítico y supo inculcar el sentido de servicio al prójimo que es razón de ser y fin último de nuestra ciencia, en todos los que hoy nos enorgullecemos de haber estado a su lado en nuestra vida quirúrgica. La única regla que nos dictó cuando entramos al Servicio fue: “Los pacientes 
se visitan de mañana y se pasa contra visita en la noche”. Todo lo hacíamos por la razón del afecto y por el ejemplo de su generosidad y rectitud de proceder. Generosidad que no se expresaba en palabras sino en gestos concretos y silenciosos. Jamás dejó solos a sus alumnos y colegas en situaciones difíciles o límites a las que estuvieran enfrentados, tanto asistenciales como materiales. Y esto último, con una discreción encomiable.

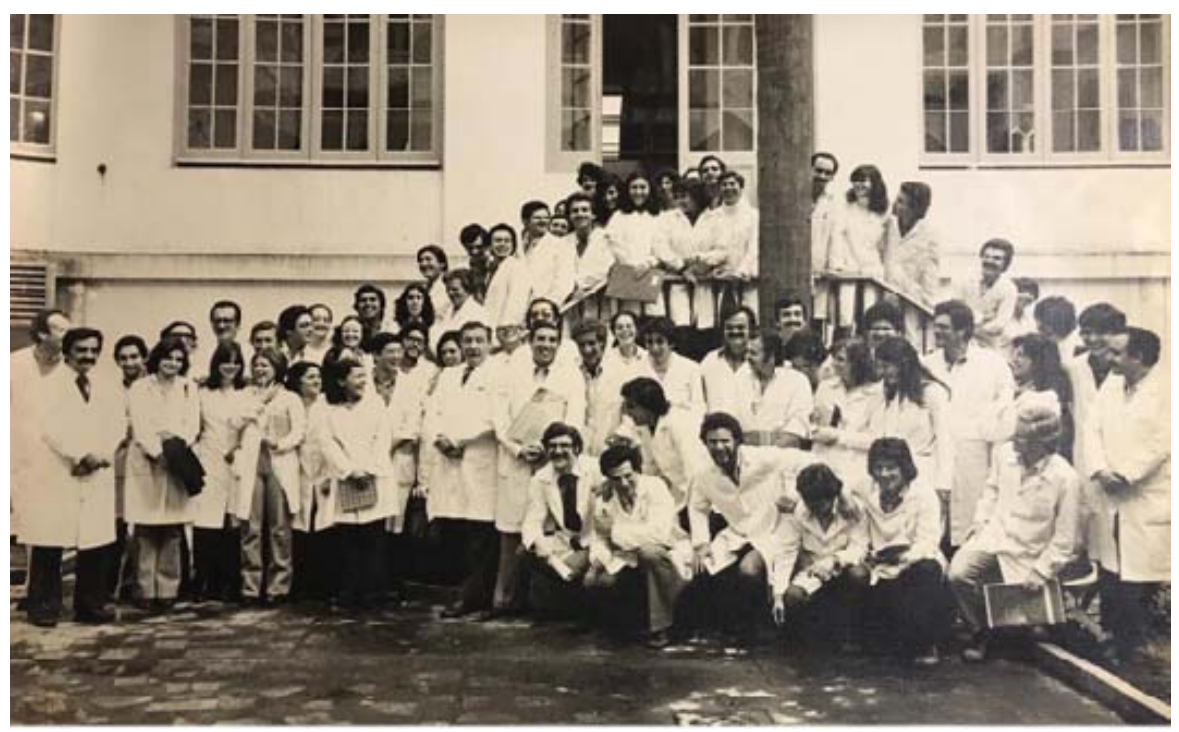

Foto 5

Como cirujano era poseedor de una extraordinaria habilidad quirúrgica que agregada a sus excepcionales conocimientos de la anatomía, de la patología y de las soluciones tácticas para cada situación, hacía que ayudarlo a operar fuera un placer y una fuente inagotable de aprendizaje; siempre que uno hubiera aprendido las voces de mando que se imparten en los veleros. Operaba rápidamente pero siempre enseñaba que los diferentes tiempos de una operación, ejemplificaba, tenían diferentes ritmos musicales. Había partes que debían hacerse extremando las precauciones y dedicándoles el tiempo que fuera necesario como un minué y otros como a ritmo de samba. Al final decía, que había que amarinar el abdomen, es decir dejar todo revisado cuidadosamente y todo ordenado, cuando quedaban drenajes ver que funcionaran, eso permitía dormir tranquilo al cirujano.

Dedicó la mayor parte de su actividad como cirujano al CASMU, institución de asistencia colectiva, propiedad de los médicos, donde culminó su carrera como Jefe del Departamento de Cirugía.

Los Ateneos donde disimulaba sus clases eran didácticos y pintorescos, llenos de dibujos, aforismos, anécdotas y hechos históricos que servían para que la patología y las conductas terapéuticas quedaran en la memoria de estudiantes y de los propios cirujanos jóvenes. Pero la mejor parte era el café que tomábamos el staff permanente del Servicio, en su escritorio al finalizar los mismos, donde se 
discutían procedimientos, resultados, errores y temas de estudio que eran repartidos, casi como premios y donde señalaba una y otra vez, como permanente estímulo para el estudio que: ”En ciencia no existe el principio de autoridad”.

Sus descripciones operatorias eran generalmente ilustradas con dibujos y esquemas que traducían su facilidad para el dibujo y la claridad de sus ideas. Esa habilidad natural la cultivó dedicándose con placer a la pintura. Con el tiempo se volvió un respetable marinista, exponiendo en múltiples oportunidades.

Hombre de la Sociedad de Cirugía, a la que presidió con honor. Alma mater de su revista “Cirugía del Uruguay” de la que fue editor por dos décadas, realizando la titánica tarea de mantenerla al día y de lograr que fuera intercambiada por las más prestigiosas publicaciones extranjeras ayudando así, a la educación de todos nuestros cirujanos. Y luego estimuló a sus alumnos a ocupar su lugar, celebrando con justicia el "Brindis de Gorgias”. Presidió el XXX Congreso Uruguayo de Cirugía.

De espíritu jovial e inquieto, se escondía detrás de un gesto adusto que caía frente a la calidez con que atendía a sus enfermos, quienes siempre ocupaban el centro de sus preocupaciones.

Fue Presidente de la Academia Nacional de Medicina para la cual fue designado en 1991. Profesor Emérito de la Facultad de Medicina y designado como Maestro de Cirugía, por sus colegas. Miembro de Honor de numerosas Sociedades y Academias de América y de Europa. Entre Tesis, trabajos originales y casuísticos realizó más de 240 publicaciones y fue invitado a colaborar con

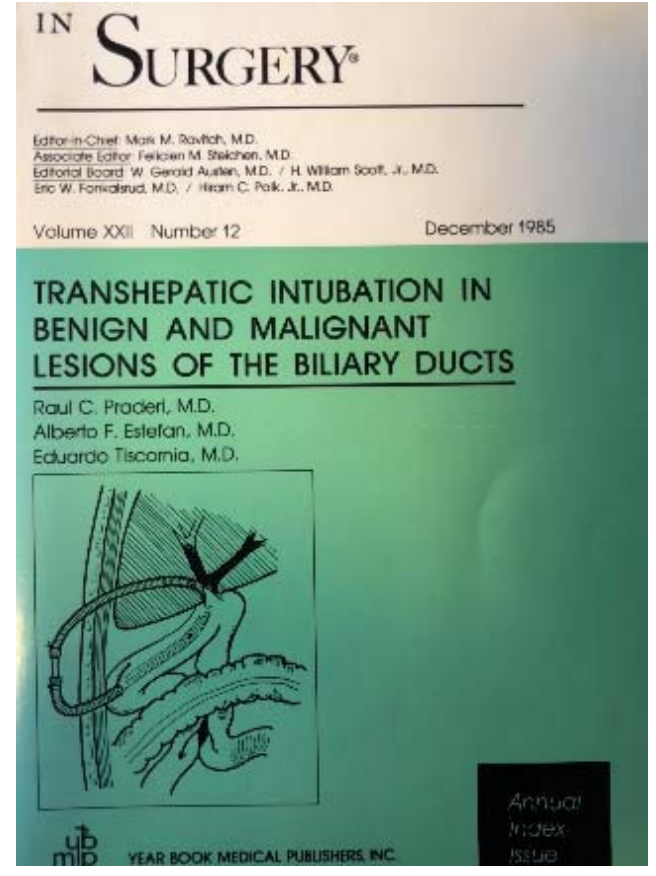
capítulos en tratados de referencia de autores extranjeros. Relator invitado en múltiples congresos nacionales y extranjeros.

Polemizó, reivindicó e hizo reconocer los logros de la cirugía rioplatense y aún europea con los líderes de la cirugía anglosajona Warren, Rodney Smith, Mark Ravitch, Glenn, Longmire. Fue invitado por Hess a escribir algunos capítulos de su tratado. Bismuth, Patel, Leger y Couinaud en Francia, Goñi Moreno, Mainetti, Defelitto, Sugasti, Magaldi, Etala y Mazzariello en Argentina fueron sus amigos, consejeros y afectuosos críticos de sus trabajos.

Foto 6 
Sus mayores contribuciones fueron en el campo de la cirugía hepática, biliar y pancreática, donde contribuyó con diversas prioridades tácticas y técnicas en el área de la cirugía de las estenosis biliares benignas y en el tratamiento de los tumores de la vía biliar, específicamente en la utilización de la intubación transtumoral como método de paliación de las ictericias y en el "calibrado" de las anastomosis bilio-digestivas en el tratamiento de las lesiones de las vías biliares.

Para las mismas utilizaba una variación del asa de Braun Hivet Warren y que publicara en 1963. De extraordinaria sencillez y versatilidad y que todos en su clínica al utilizarla la habíamos bautizado, en son de broma, de Braun Hivet Warren modificada por uno de nosotros.

Su cultura renacentista, la expresó por su amor a los libros y a la riquísima biblioteca que formó con paciencia de coleccionista y su desprendimiento, en como la misma era puesta a disposición de quien lo requiriera. Fue un viajero inveterado y un ameno relator de las innumerables experiencias culturales que los mismos le brindaban.

En su juventud cultivó como deporte la navegación a vela en el "Pintarroja"

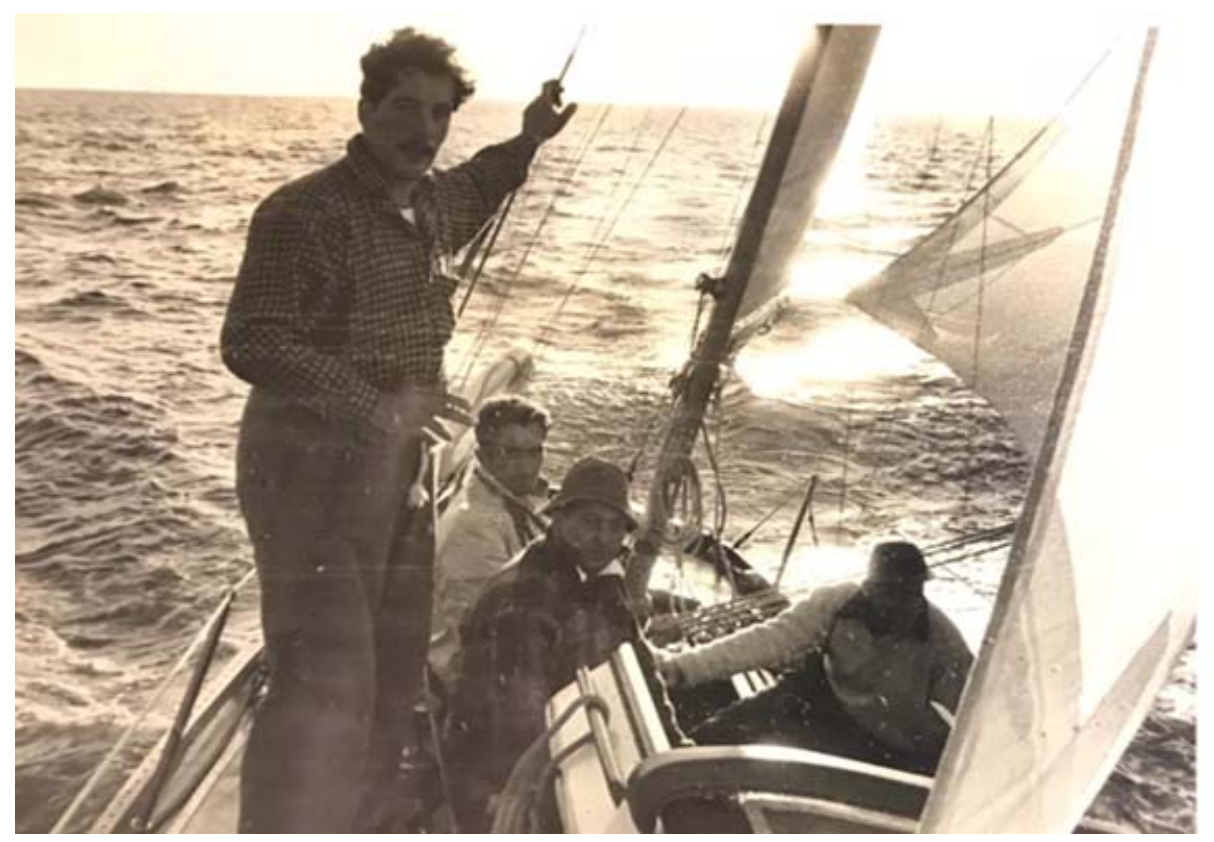

Foto 7

Luego prosiguió con el canotaje, recorrió así, acompañado de sus inseparables amigos los hermanos Parietti, Vivo, Durán y Morassi, la inmensa mayoría de los cursos de agua de nuestro país. 


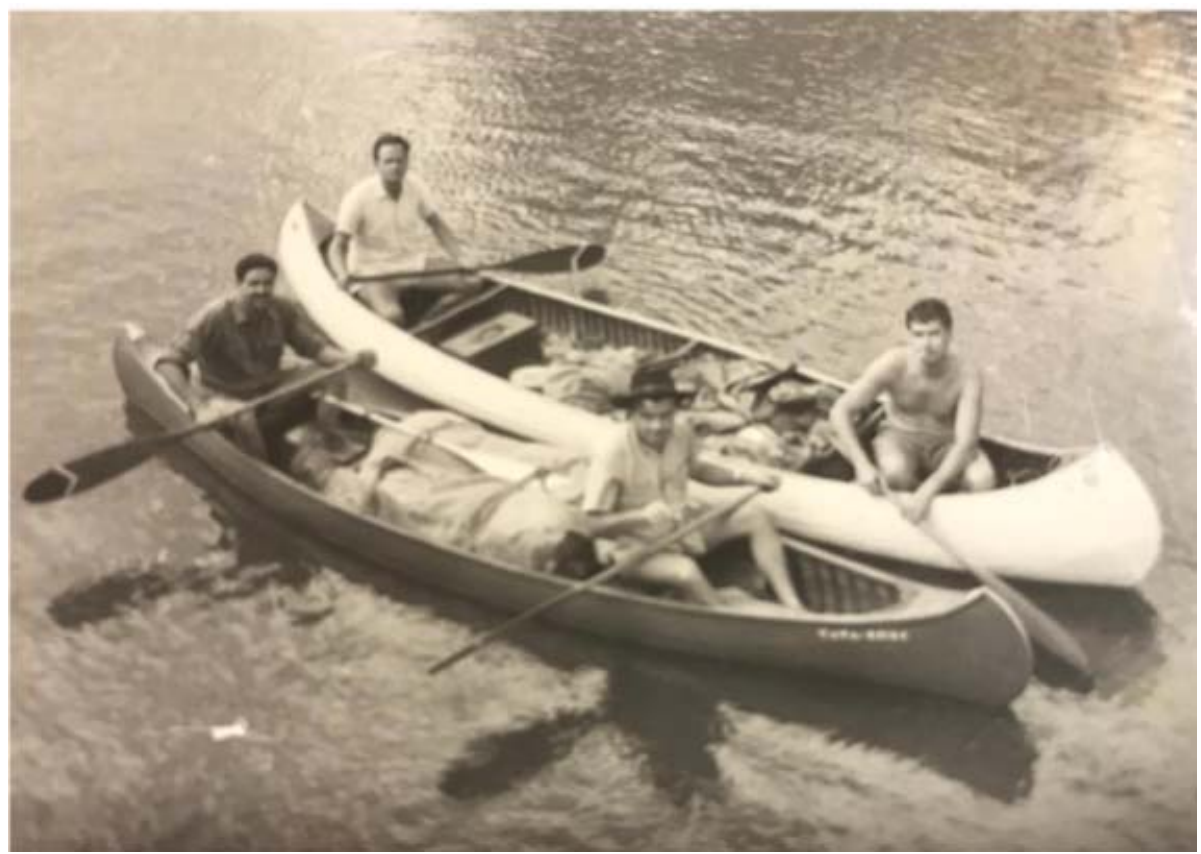

Foto 8

Fruto de esta exploración y la necesidad permanente del estudio que imbuía su personalidad, fue la publicación de varios libros sobre la hidrografía del Uruguay. De su estudio de la historia naval surgen múltiples artículos sobre veleros y episodios descollantes de la navegación en nuestras latitudes.

Y en tiempos duros, cuando todos callaban, levantó su voz valiente para defender a amigos y adversarios con la convicción de su ideal liberal y democrático. Ayudó a quienes permanecieron, a quienes se fueron y a todos los que lo requirieron.

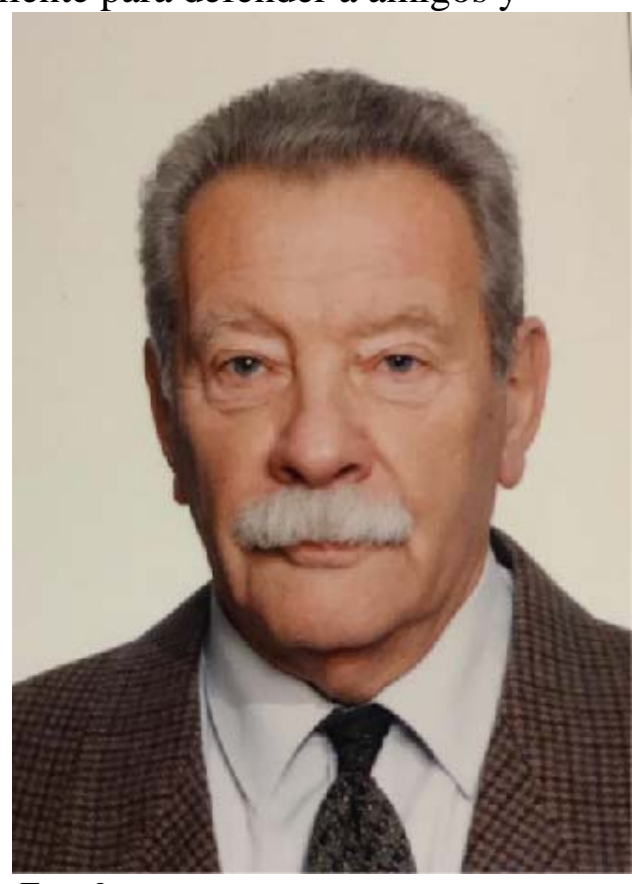

Foto 9 
No mostró miedo, cuando los terroristas invadieron su hogar, en venganza por cumplir con la Ley, antes del golpe de estado, ni dudó después, durante la dictadura, en defender la

Constitución y los derechos humanos.

Lo sobreviven sus tres hijos, Rosina, Gonzalo y Santiago, sus ocho nietos

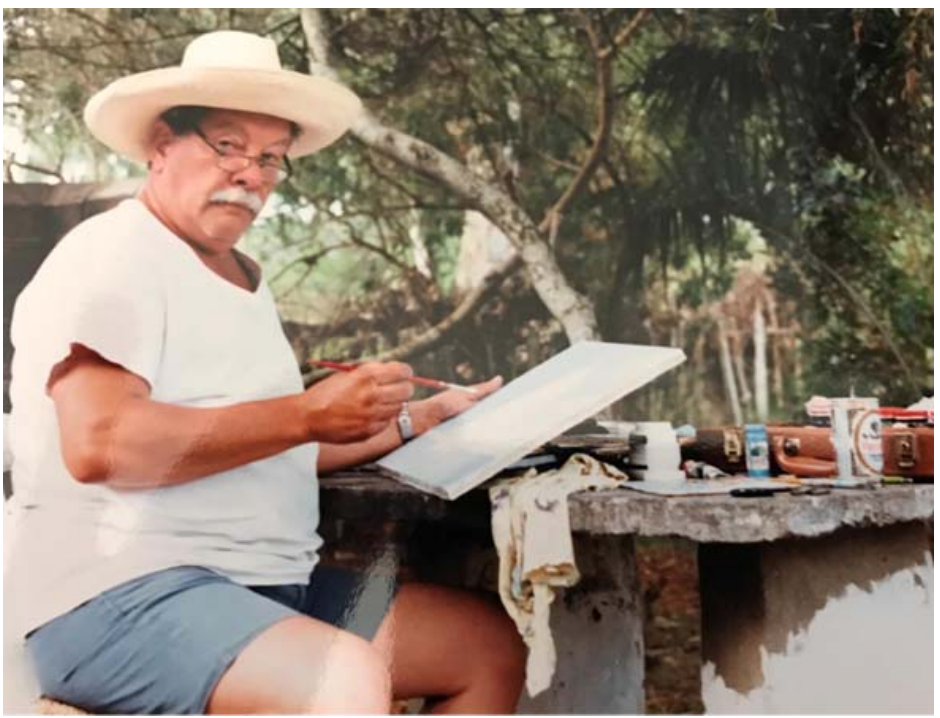

Foto 10

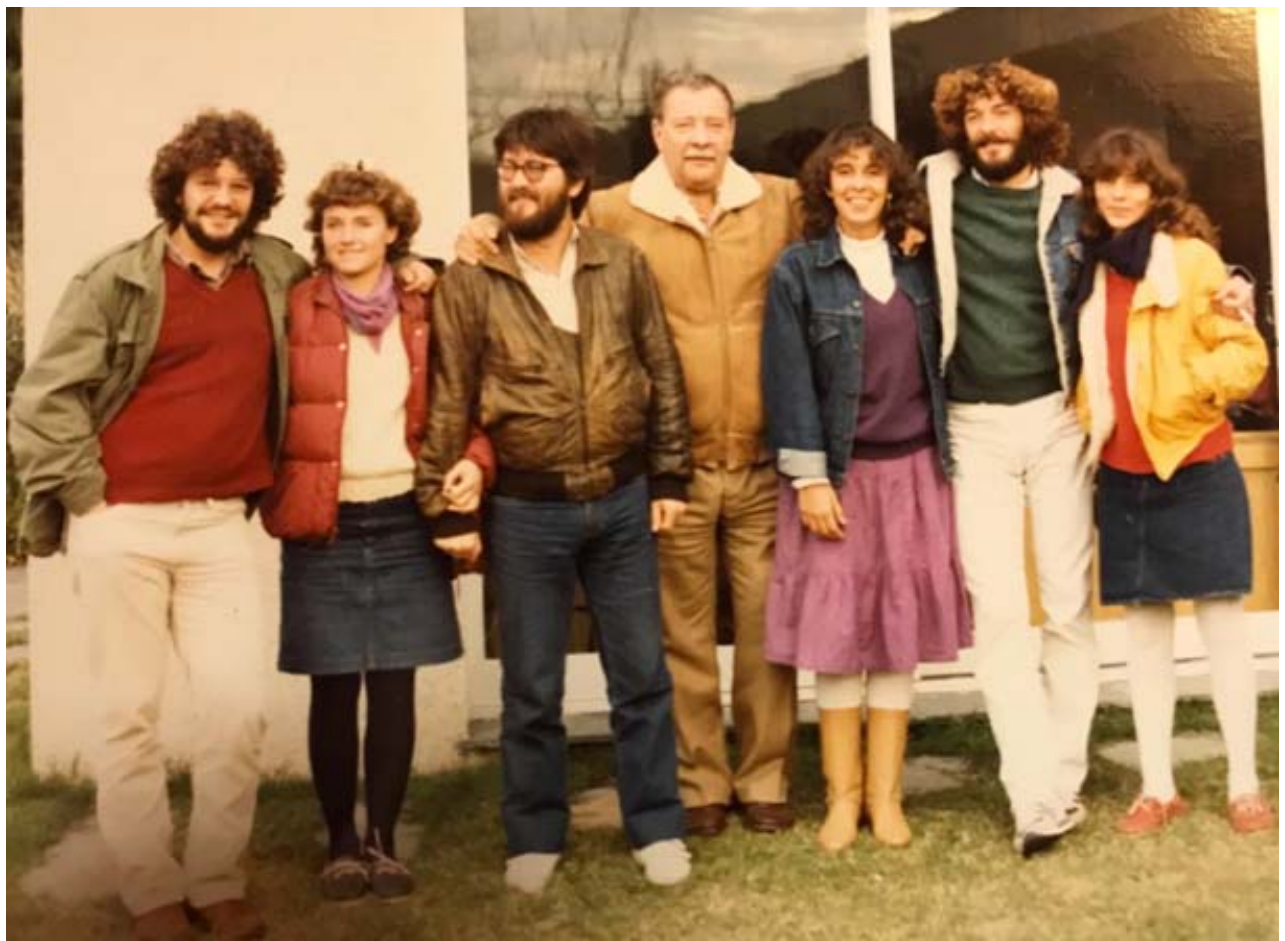

Foto 11

Y sus alumnos que conservarán por siempre su memoria con afecto y admiración.

Dres. Jorge Pomi y Gustavo Bogliaccini 7 de Noviembre de 2018 